\title{
Patient-reported outcomes of occipitocervical and atlantoaxial fusions in children
}

\author{
Aditya Vedantam, MD, ${ }^{1}$ Daniel Hansen, MD, ${ }^{1}$ Valentina Briceño, RN, ${ }^{1}$ Alison Brayton, $\mathrm{RN},{ }^{1}$ and \\ Andrew Jea, MD ${ }^{1,2}$ \\ 1Division of Pediatric Neurosurgery, Texas Children's Hospital, Department of Neurosurgery, Baylor College of Medicine, \\ Houston, Texas; and 'Section of Pediatric Neurosurgery, Riley Hospital for Children, Indiana University School of Medicine \\ Department of Neurosurgery, Goodman Campbell Brain and Spine, Indianapolis, Indiana
}

\begin{abstract}
OBJECTIVE There is limited literature on patient-reported outcomes (PROs) and health-related quality of life (HRQOL) outcomes in pediatric patients undergoing surgery for craniovertebral junction pathology. The aim of the present study was to assess surgical and quality of life outcomes in children who had undergone occipitocervical or atlantoaxial fusion.

METHODS The authors retrospectively reviewed the demographics, procedural data, and outcomes of 77 consecutive pediatric patients who underwent posterior occipitocervical or atlantoaxial fusion between 2008 and 2015 at Texas Children's Hospital. Outcome measures (collected at last follow-up) included mortality, neurological improvement, complications, Scoliosis Research Society Outcomes Measure-22 (SRS-22) score, SF-36 score, Neck Disability Index (NDI), and Pediatric Quality of Life Inventory (PedsQL). Multivariate linear regression analysis was performed to identify factors affecting PROs and HRQOL scores at follow-up.
\end{abstract}

RESULTS The average age in this series was $10.6 \pm 4.5$ years. The median follow-up was 13.9 months (range 0.5-121.5 months). Sixty-three patients (81.8\%) were treated with occipitocervical fusion, and 14 patients (18.1\%) were treated with atlantoaxial fusion. The American Spinal Injury Association (ASIA) grade at discharge was unchanged in 73 patients (94.8\%). The average PRO metrics at the time of last follow-up were as follows: SRS-22 score, $4.2 \pm 0.8$; NDI, 3.0 \pm 2.6; the parent's PedsQL (ParentPedsQL) score, $69.6 \pm 22.7$, and child's PedsQL score, $75.5 \pm 18.7$. Multivariate linear regression analysis revealed that older age at surgery was significantly associated with lower SRS-22 scores at follow-up ( $B=-0.06, p=0.03)$, and the presence of comorbidities was associated with poorer ParentPedsQL scores at follow-up $(B=-19.68, p=0.03)$.

CONCLUSIONS This study indicates that occipitocervical and atlantoaxial fusions in children preserve neurological function and are associated with acceptable PROs and ParentPedsQL scores, considering the serious nature and potential for morbidity in this patient population. However, longer follow-up and disease-specific scales are necessary to fully elucidate the impact of occipitocervical and atlantoaxial fusions on children.

http://thejns.org/doi/abs/10.3171/2016.8.PEDS16286

KEY WORDS surgical outcomes; patient-reported outcomes; health-related quality of life; occipitocervical fusion; atlantoaxial fusion; traumatic atlantooccipital dislocation; pediatric neurosurgery; spine

$\mathrm{D}$ ESPITE the unique anatomy and potential for considerable morbidity, surgery for pediatric craniovertebral junction pathology is largely associated with successful outcomes. ${ }^{13}$ The majority of prior studies have focused on surgical outcomes, such as the rate of fusion, rate of complications, and general clinical outcome measures. ${ }^{1,9,13,20}$ With the advancements in surgical technique for craniovertebral junction pathology, there is a need to better determine the clinical and global effectiveness of our surgical intervention.

Changes in the current health care environment have led to an increased focus on value-based interventions and quantifying patient-reported outcomes (PROs) after surgery. A recent review of the literature, however, revealed that few studies have reported such outcome measures for pediatric neurosurgical patients, even though the use

ABBREVIATIONS ASIA = American Spinal Injury Association; ChildPedsQL = child-reported PedsQL; HRQOL = health-related quality of life; IONM = intraoperative neuromonitoring; MCS = Mental Component Summary; NDI = Neck Disability Index; ParentPedsQL = parent-reported PedsQL; PCS = Physical Component Summary; PedsQL = Pediatric Quality of Life Inventory; PRO = patient-reported outcome; SRS-22 = Scoliosis Research Society Outcomes Measure-22.

SUBMITTED May 20, 2016. ACCEPTED August 5, 2016.

INCLUDE WHEN CITING Published online October 28, 2016; DOI: 10.3171/2016.8.PEDS16286. 
of PROs and health-related quality of life (HRQOL) outcomes for other pediatric conditions is increasing. ${ }^{10}$ To the best of our knowledge, the use of PRO and HRQOL tools has not been previously undertaken for pediatric patients undergoing surgery for craniovertebral junction pathology.

The aim of the present study was to perform an assessment of surgical interventions in a series of children with craniovertebral junction pathology, with an emphasis on measuring PROs and HRQOL outcomes.

\section{Methods}

We reviewed all consecutive patients (age $\leq 18$ years) who underwent occipitocervical or atlantoaxial fusion performed by the pediatric neurosurgery service at Texas Children's Hospital from 2008 to 2015. This study received approval from the Baylor College of Medicine Institutional Review Board.

All patients underwent surgery via a standard posterior approach, and no patient underwent a combined anteriorposterior surgery. The surgical technique for occipitocervical fusion performed by our team has been described previously. ${ }^{11,12,23}$ In brief, a midline posterior approach with subperiosteal exposure of the occiput and required cervical levels was performed. Occipital screws, C-1 lateral mass, and C-2 pars or pedicle screws were placed under fluoroscopic guidance. For fusions extending to lower levels, the relevant anatomy was exposed, and lateral mass or laminar screws were placed in a standard fashion for the cervical levels.

\section{Clinical Outcome Measures}

Patient demographics, disease characteristics, treatment variables, readmissions or reoperations, and surgical morbidity and mortality were recorded for each case. Postoperative HRQOL outcomes were captured at the most recent clinic visit. PRO instruments included Scoliosis Research Society Outcomes Measure-22 (SRS-22), SF-36 Physical Component Summary (PCS), SF-36 Mental Component Summary (MCS), neck disability index (NDI), and Pediatric Quality of Life Inventory (PedsQL) parent-reported score (ParentPedsQL) and child-reported score (ChildPedsQL). All PROs were obtained with the help of clinical research personnel at the most recent clinic visit. The SRS-22, SF-36 PCS, SF-36 MCS, and NDI forms were given to patients and parents for self-administration. For the ChildPedsQL, age-specific forms (ages $5-7,8-12$, and 13-18 years) were completed by children. For children in the 5- to 7-years of age group, the instructions and items were read out loud to the child and his or her answers were recorded. For children in the age groups 8-12 years and 13-18 years, self-administration was encouraged. If cognitive impairments prevented the child from completing the form, data for the ChildPedsQL form were not recorded. Parents were given the ParentPedsQL forms to complete.

\section{Statistical Analysis}

Descriptive statistics (mean $\pm \mathrm{SD}$ ) were computed as necessary. Multivariate linear regression analysis was per- formed for the SRS-22, ParentPedsQL, and NDI scores to determine the effect of age, sex, diagnosis, preoperative American Spinal Injury Association (ASIA) grade, number of levels fused, intraoperative complications, as well as presence of comorbidities; $p$ values were considered significant at $<0.05$ (Student t-test). Analysis was done using SPSS Statistics (version 20, IBM Corp.).

\section{Results}

\section{Patient Population}

A total of 77 patients were included in our study. The mean age \pm SD at the time of occipitocervical or atlantoaxial fusion was $10.6 \pm 4.5$ years. Forty-one patients (53.2\%) were boys. Baseline demographic and clinical data are shown in Table 1.

\section{Operative Treatment}

Sixty-three (81.8\%) of the 77 patients were treated with occipitocervical fusion. All patients underwent spinal instrumentation. The average number of levels fused was 2.4 \pm 0.9 . Most procedures lasted 2 to 4 hours $(n=64,83.1 \%$ ). The mean estimated blood loss was $84.0 \pm 156.7 \mathrm{ml}$. Intraoperative neuromonitoring (IONM) was used in the majority of cases $(n=72,93.5 \%)$. The overall intraoperative complication rate was $14.3 \%$. The most common intraoperative complications encountered in our series included durotomy (3 cases) and loss/change in IONM signals (3 cases) (Table 2).

\section{Outcomes}

Clinical follow-up was available for 57 patients at a median duration of 13.9 months (1.4-121.5 months), with a minimum 6-month follow-up for more than $80 \%$ of patients. Two patients (2.6\%) died during postoperative follow-up. One patient sustained a cardiopulmonary arrest intraoperatively due to suspected primary cardiac event and died on postoperative Day 2. Another patient developed postoperative propofol infusion syndrome and died on postoperative Day 43.

Neurological stability with no change in ASIA grade at discharge was seen in 73 patients $(94.8 \%)$. One patient who underwent a supplementary occipitocervical fusion after resection of clival chordoma had an improvement from ASIA Grade D to Grade E, and another patient with traumatic atlantooccipital dislocation improved from Grade B to Grade D at discharge. No patient had a worsened ASIA grade at discharge. During the postoperative period, the most common complications were CSF leak (4 cases), dysphagia ( 2 cases, including 1 patient who required a temporary gastrostomy tube), and pneumonia/ sepsis ( 2 cases) (Table 2). The majority of patients $(n=65$, $84.4 \%$ ) were discharged home after surgery.

\section{PROs and HRQOL Outcomes and Predictors}

The mean PROs and HRQOL outcome scores are shown in Table 3. Multivariate linear regression analysis (Table 4) revealed that increased age at surgery was significantly associated with lower SRS-22 scores (i.e., worse outcome) at follow-up $(\mathrm{B}=-0.06, \mathrm{p}=0.03)$. Multivariate 
TABLE 1. Preoperative and demographic data for patients undergoing occipitocervical and atlantoaxial fusion

\begin{tabular}{|c|c|}
\hline Preop Data & No. of Patients (\%) \\
\hline \multicolumn{2}{|l|}{ Age (yrs) } \\
\hline $1-6$ & $17(20.7)$ \\
\hline $6-12$ & $32(41.6)$ \\
\hline $12-18$ & $28(36.4)$ \\
\hline \multicolumn{2}{|l|}{ Etiology } \\
\hline Congenital & $48(62.3)$ \\
\hline Trauma & $25(32.5)$ \\
\hline Tumor & $3(3.9)$ \\
\hline Deformity & $1(1.3)$ \\
\hline \multicolumn{2}{|l|}{ Diagnosis } \\
\hline Occipitocervical instability & $32(41.6)$ \\
\hline Basilar invagination & $10(13.0)$ \\
\hline Os odontoideum & $10(13.0)$ \\
\hline Atlantooccipital dissociation & $9(11.7)$ \\
\hline Atlantooccipital instability & $7(9.1)$ \\
\hline Odontoid fracture & $6(7.8)$ \\
\hline Chordoma, clivus & $2(2.6)$ \\
\hline Osteosarcoma, skull base & $1(1.3)$ \\
\hline \multicolumn{2}{|l|}{ Preop ASIA grade } \\
\hline A & $1(1.3)$ \\
\hline$B$ & $1(1.3)$ \\
\hline C & $4(5.2)$ \\
\hline $\mathrm{D}$ & $11(14.3)$ \\
\hline$E$ & $60(77.9)$ \\
\hline \multicolumn{2}{|l|}{ Discharge ASIA grade } \\
\hline A & $1(1.3)$ \\
\hline B & $0(0)$ \\
\hline C & $4(5.2)$ \\
\hline $\mathrm{D}$ & $10(13.0)$ \\
\hline$E$ & $60(77.9)$ \\
\hline NA & $2(2.6)$ \\
\hline \multicolumn{2}{|l|}{ Comorbidities } \\
\hline None & $29(37.7)$ \\
\hline Syndromic disorders & $9(11.7)$ \\
\hline Down syndrome & $7(9.1)$ \\
\hline Traumatic brain injury & $6(7.8)$ \\
\hline Chiari Type I malformation & $6(7.8)$ \\
\hline Malignancy & $4(5.2)$ \\
\hline Cerebral palsy & $2(2.6)$ \\
\hline Congenital heart disease & $2(2.6)$ \\
\hline Juvenile arthritis & $2(2.6)$ \\
\hline Spina bifida & $2(2.6)$ \\
\hline Other* & $8(10.3)$ \\
\hline
\end{tabular}

$\mathrm{NA}=$ not available

* Other comorbidities included brachial plexus injury $(n=1)$, von Willebrand's Disease $(n=1)$, long bone fracture $(n=1)$, encephalocele $(n=1)$, developmental delay $(n=1)$, skeletal dysplasia $(n=1)$, nonaccidental trauma $(n=1)$, and osteopenia $(n=1)$.
TABLE 2. Surgical treatment variables, disposition, and complications for 77 pediatric patients undergoing occipitocervical and atlantoaxial fusion

\begin{tabular}{lc}
\hline \multicolumn{1}{c}{ Surgical Treatment Variables } & No. of Patients (\%) \\
\hline Fusion type & \\
\hline Occipitocervical & $63(81.8)$ \\
\hline Atlantoaxial & $14(18.1)$ \\
\hline Length of op (hrs) & $1(1.3)$ \\
\hline$<2$ & $64(83.1)$ \\
\hline $2-4$ & $11(14.3)$ \\
\hline $4-6$ & $1(1.3)$ \\
\hline$>6$ & \\
\hline Intraop complications & $2(2.6)$ \\
\hline Vertebral artery injury & $3(3.9)$ \\
\hline Durotomy & $3(3.9)$ \\
\hline Loss/change in IONM signals & $4(5.2)$ \\
\hline Other* & \\
\hline Discharge disposition & $65(84.4)$ \\
\hline Home & $10(13)$ \\
\hline Inpatient rehabilitation & $2(2.6)$ \\
\hline Death & $1(1.3)$ \\
\hline Postop complications & $4(5.2)$ \\
\hline Deep vein thrombosis/pulmonary embolism & $2(2.6)$ \\
\hline CSF leak & $2(2.6)$ \\
\hline Pneumonia/sepsis & $1(1.3)$ \\
\hline Dysphagia & $2(2.6)$ \\
\hline Superficial surgical site infection & \\
\hline Reop & \\
\hline
\end{tabular}

* Emergent tracheostomy $(n=1)$, acute cardiopulmonary failure $(n=1)$, aborted posterior fusion $(n=1)$, and cracked lateral mass $(n=1)$.

linear regression analysis showed poorer ParentPedsQL scores (i.e., worse outcome) at follow-up in patients with associated comorbidities $(B=-19.68, p=0.03)$. No significant predictors for the NDI score at follow-up were noted using the same regression model. Number of levels fused, preoperative ASIA grade, intraoperative complications, and diagnosis were not associated with PROs or HRQOL outcome scores.

\section{Discussion}

The present study describes PROs and HRQOL outcome scores in a consecutive series of pediatric patients undergoing surgery for craniovertebral pathology. The majority of patients had stable neurological examination results postoperatively and showed favorable PROs and HRQOL outcome scores at follow-up. Age at surgery and the presence of comorbidities were found to be significant predictors of PROs and HRQOL outcome scores.

The mean PROs and HRQOL outcomes in our series were similar to the mean scores after other pediatric neurosurgical procedures. In our cohort, the average SRS-22 score (4.2) was comparable to the mean postoperative SRS22 scores reported for patients with adolescent idiopathic 
TABLE 3. PROs and HRQOL outcomes in pediatric patients undergoing occipitocervical and atlantoaxial fusion

\begin{tabular}{lcc}
\hline Outcome Tool & No. of Patients & Mean (SD) \\
\hline SRS-22 & 42 & $4.2(0.8)$ \\
\hline SF-36 PCS & 13 & $49.6(10.6)$ \\
\hline SF-36 MCS & 13 & $52.5(12.7)$ \\
\hline NDI & 36 & $3.0(2.6)$ \\
\hline ParentPedsQL & 36 & $69.6(22.7)$ \\
\hline ChildPedsQL & 26 & $75.5(18.7)$ \\
\hline
\end{tabular}

scoliosis. ${ }^{4}$ The average SF-36 PCS score in this study was similar to values in pediatric patients who underwent fusion for scoliosis, ${ }^{5,27}$ as well as in children undergoing surgery for lumbar disc disease. ${ }^{6}$ The average PedsQL score in the present study compared favorably with good outcomes obtained in children with adolescent idiopathic scoliosis ${ }^{14}$ and intramedullary spinal cord tumors. ${ }^{24}$ These results show that expected quality of life outcomes after craniovertebral junction surgery in children are equivalent to outcomes seen in other pediatric spine surgeries.

The pediatric spine literature has been sparse in analyzing effects of occipitocervical and atlantoaxial fusion on quality of life in children. To the best of our knowledge, this study is the first to examine patient-centered characterization of pain, disability, and quality of life after occipitocervical and atlantoaxial fusions in children. Since craniovertebral junction fusion leads to a decrease in the range of motion of the cervical spine, ${ }^{29}$ it is to be expected that quality of life scores would be low after surgery. The results of this study, however, indicate that although craniovertebral junction pathology is associated with morbidity, surgery is associated with acceptable quality of life scores at intermediate follow-up. Given the number of active years in a child after surgery, long-term HRQOL outcome scores are necessary to better evaluate the impact of occipitocervical and atlantoaxial fusions on quality of life over time.

Atlantoaxial and craniovertebral instabilities represent unique challenges in their diagnosis and management, especially in the pediatric population, where smaller vertebral body size, abnormal anatomy caused by craniover- tebral anomalies, and an immature spine are important issues encountered by pediatric spine surgeons. ${ }^{20}$ Numerous authors have shown the feasibility of achieving occipitocervical and atlantoaxial fusions even in the youngest of patients with rigid spinal instrumentation. ${ }^{7,15}$ In our series, all patients had spinal instrumentation incorporated as part of their fusion. Our results for neurological outcomes, as well as surgical complication rates, are similar to previous studies. ${ }^{13,19}$ Furthermore, significantly improved prehospital care for cases of traumatic atlantooccipital dislocation, hospital care for patients with traumatic and nontraumatic spinal cord injuries, and advances in surgical technique for placement of spinal instrumentation in children ${ }^{17}$ have resulted in decreased morbidity and mortality for pediatric patients undergoing occipitocervical and atlantoaxial fusions.

Our study showed that older age is associated with lower SRS-22 scores at follow-up, and a similar trend has been observed in patients with idiopathic scoliosis. ${ }^{22}$ It has been shown that younger patients are more affected by the ceiling effects of the SRS-22 questionnaire. This may be attributable to an early diagnosis in young children, who experience less pain, less compromised function, and better mental scores than older patients. ${ }^{2}$ Additionally, it is likely that older children have a decreased ability to adapt to the decreased range of motion after fusion. The presence of comorbidities was associated with lower ParentPedsQL scores in our series, similar to HRQOL studies from other disease states. ${ }^{3,16}$ Comorbidities decreased HRQOL scores and affect generic HRQOL tools, such as the ParentPedsQL, more than disease-specific tools. ${ }^{30}$ Comorbidities contribute additional physical and psychological burden for parents and need to be accounted for in determining HRQOL outcomes in children. The identification and treatment of these comorbidities are important, and surgeons need to be a part of a comprehensive care program for these children.

The primary limitations of our study lie in the small sample size, attrition rate, and retrospective design. The lack of long-term follow-up PRO data is another limitation of this study. Since we tried to use a number of PRO instruments at follow-up, we had difficulty ensuring that patients or parents completed all the PROs, which led to missing data values. We did not have data on preopera-

TABLE 4. Multivariate linear regression analysis to determine factors associated with PROs and HRQOL outcomes at follow-up after occipitocervical and atlantoaxial fusion in children

\begin{tabular}{|c|c|c|c|c|c|c|}
\hline \multirow[b]{2}{*}{ Variable } & \multicolumn{2}{|c|}{ SRS-22 } & \multicolumn{2}{|c|}{ ParentPedsQL } & \multicolumn{2}{|c|}{$\mathrm{NDI}$} \\
\hline & B & $p$ Value & B & $p$ Value & B & p Value \\
\hline Age at op & -0.06 & $0.03^{*}$ & -0.19 & 0.82 & 0.10 & 0.39 \\
\hline $\operatorname{Sex}(F / M)$ & 0.23 & 0.35 & 3.35 & 0.70 & -1.0 & 0.31 \\
\hline Diagnosis† & -0.02 & 0.87 & -2.08 & -0.44 & -0.26 & 0.49 \\
\hline Comorbidities (no/yes) & -0.23 & 0.38 & 19.68 & $0.03^{*}$ & -0.07 & 0.95 \\
\hline Preop ASIA grade & 0.23 & 0.34 & 4.83 & 0.38 & -0.53 & 0.64 \\
\hline No. of levels fused & -0.02 & 0.89 & -1.58 & 0.71 & -0.63 & 0.239 \\
\hline Intraop complications (no/yes) & -0.06 & 0.87 & 3.89 & 0.80 & 1.35 & 0.54 \\
\hline
\end{tabular}


tive scores for the PRO instruments and were unable to define the change in PRO scores after surgery. The ASIA grade has been previously used to define the neurological status in patients undergoing occipitocervical fusion. ${ }^{18,21,26}$ Although this scale is more appropriate for patients who have sustained a spinal cord injury, it does provide a standardized tool to evaluate neurological deficits for these patients. The instruments used in this study were not disease specific and possibly did not address the specific problems associated with occipitocervical fusion. While the SRS$22,{ }^{8} \mathrm{SF}-36,{ }^{28}$ and NDI ${ }^{25}$ have been used in a few prior pediatric studies, these scales are not ideal for children. Additionally, missing data for the SF-36, NDI, and ChildPedsQL forms may have limited the ability to achieve statistically significant associations in our analysis. Currently, a concise, validated disease-specific HRQOL scale for craniovertebral junction disorders in children is lacking. The present study used the most widely used scalesSRS-22, NDI, SF-36, and the PedsQL - to describe the quality of life outcomes in this patient population; yet, there is a need to develop scales that are sensitive to the specific issues concerning these children. In this study, we have provided an early description of quality of life outcomes in this patient population and expect to carry this study forward by implementing a disease-specific scale to assess outcomes for children undergoing craniovertebral junction surgery.

\section{Conclusions}

Occipitocervical and atlantoaxial fusions for the treatment of craniocervical junction disorders in children are relatively safe and effective procedures. They are associated with acceptable PROs and HRQOL scores, considering the serious nature and potential for morbidity in this patient population. However, longer follow-up and diseasespecific scales are necessary to elucidate the full impact of occipitocervical and atlantoaxial fusions on children.

\section{References}

1. Anderson RC, Ragel BT, Mocco J, Bohman LE, Brockmeyer DL: Selection of a rigid internal fixation construct for stabilization at the craniovertebral junction in pediatric patients. J Neurosurg 107 (1 Suppl):36-42, 2007

2. Asher M, Min Lai S, Burton D, Manna B: The reliability and concurrent validity of the Scoliosis Research Society-22 patient questionnaire for idiopathic scoliosis. Spine (Phila Pa 1976) 28:63-69, 2003

3. Baca CB, Vickrey BG, Caplan R, Vassar SD, Berg AT: Psychiatric and medical comorbidity and quality of life outcomes in childhood-onset epilepsy. Pediatrics 128:e1532e1543, 2011

4. Bastrom TP, Bartley C, Marks MC, Yaszay B, Newton PO: Postoperative perfection: ceiling effects and lack of discrimination with both SRS-22 and -24 outcomes instruments in patients with adolescent idiopathic scoliosis. Spine (Phila Pa 1976) 40:E1323-E1329, 2015

5. Desai SK, Sayama C, Vener D, Brayton A, Briceño V, Luerssen TG, et al: The feasibility and safety of using sublaminar polyester bands in hybrid spinal constructs in children and transitional adults for neuromuscular scoliosis. J Neurosurg Pediatr 15:328-337, 2015

6. Durham SR, Sun PP, Sutton LN: Surgically treated lumbar disc disease in the pediatric population: an outcome study. $\mathbf{J}$ Neurosurg 92 (1 Suppl): 1-6, 2000

7. Fargen KM, Anderson RC, Harter DH, Angevine PD, Coon VC, Brockmeyer DL, et al: Occipitocervicothoracic stabilization in pediatric patients. J Neurosurg Pediatr 8:57-62, 2011

8. Farley FA, Li Y, Jong N, Powell CC, Speers MS, Childers DM, et al: Congenital scoliosis SRS-22 outcomes in children treated with observation, surgery, and VEPTR. Spine (Phila Pa 1976) 39:1868-1874, 2014

9. Hankinson TC, Avellino AM, Harter D, Jea A, Lew S, Pincus D, et al: Equivalence of fusion rates after rigid internal fixation of the occiput to C-2 with or without C-1 instrumentation. J Neurosurg Pediatr 5:380-384, 2010

10. Hansen D, Vedantam A, Briceño V, Lam SK, Luerssen TG, Jea A: Health-related quality of life outcomes and level of evidence in pediatric neurosurgery. J Neurosurg Pediatr [epub ahead of print June 24, 2016. DOI: 10.3171/2016.3.PEDS15641]

11. Huang M, Gonda DD, Briceño V, Lam SK, Luerssen TG, Jea A: Dyspnea and dysphagia from upper airway obstruction after occipitocervical fusion in the pediatric age group. Neurosurg Focus 38(4):E13, 2015

12. Hwang SW, Gressot LV, Chern JJ, Relyea K, Jea A: Complications of occipital screw placement for occipitocervical fusion in children. J Neurosurg Pediatr 9:586-593, 2012

13. Hwang SW, Gressot LV, Rangel-Castilla L, Whitehead WE, Curry DJ, Bollo RJ, et al: Outcomes of instrumented fusion in the pediatric cervical spine. J Neurosurg Spine 17:397409,2012

14. Karakaya I, Sismanlar SG, Atmaca H, Gök U, Sarlak AY: Outcome in early adolescent idiopathic scoliosis after deformity correction: assessed by SRS-22, psychometric and generic health measures. J Pediatr Orthop B 21:317-321, 2012

15. Kennedy BC, D'Amico RS, Youngerman BE, McDowell MM, Hooten KG, Couture D, et al: Long-term growth and alignment after occipitocervical and atlantoaxial fusion with rigid internal fixation in young children. J Neurosurg Pediatr 17:94-102, 2016

16. Klassen AF, Miller A, Fine S: Health-related quality of life in children and adolescents who have a diagnosis of attention-deficit/hyperactivity disorder. Pediatrics 114:e541e547, 2004

17. Kovanda TJ, Ansari SF, Qaiser R, Fulkerson DH: Feasibility of CT-based intraoperative 3D stereotactic image-guided navigation in the upper cervical spine of children 10 years of age or younger: initial experience. J Neurosurg Pediatr 16:590-598, 2015

18. Martinez-Del-Campo E, Turner JD, Rangel-Castilla L, Soriano-Baron H, Kalb S, Theodore N: Pediatric occipitocervical fixation: radiographic criteria, surgical technique, and clinical outcomes based on experience of a single surgeon. $\mathbf{J}$ Neurosurg Pediatr [epub ahead of print June 10, 2016. DOI: 10.3171/2016.2.PEDS15544]

19. Mazur MD, Sivakumar W, Riva-Cambrin J, Jones J, Brockmeyer DL: Avoiding early complications and reoperation during occipitocervical fusion in pediatric patients. J Neurosurg Pediatr 14:465-475, 2014

20. Menezes AH: Craniocervical fusions in children. J Neurosurg Pediatr 9:573-585, 2012

21. Nockels RP, Shaffrey CI, Kanter AS, Azeem S, York JE: Occipitocervical fusion with rigid internal fixation: long-term follow-up data in 69 patients. J Neurosurg Spine 7:117-123, 2007

22. Parent EC, Dang R, Hill D, Mahood J, Moreau M, Raso J, et al: Score distribution of the Scoliosis Research Society-22 questionnaire in subgroups of patients of all ages with idiopathic scoliosis. Spine (Phila Pa 1976) 35:568-577, 2010

23. Savage JG, Fulkerson DH, Sen AN, Thomas JG, Jea A: Fixa- 
tion with C-2 laminar screws in occipitocervical or $\mathrm{C} 1-2$ constructs in children 5 years of age or younger: a series of 18 patients. J Neurosurg Pediatr 14:87-93, 2014

24. Schneider C, Hidalgo ET, Schmitt-Mechelke T, Kothbauer KF: Quality of life after surgical treatment of primary intramedullary spinal cord tumors in children. J Neurosurg Pediatr 13:170-177, 2014

25. Sellin JN, Shaikh K, Ryan SL, Brayton A, Fulkerson DH, Jea A: Clinical outcomes of the surgical treatment of isolated unilateral facet fractures, subluxations, and dislocations in the pediatric cervical spine: report of eight cases and review of the literature. Childs Nerv Syst 30:1233-1242, 2014

26. Singh SK, Rickards L, Apfelbaum RI, Hurlbert RJ, Maiman $\mathrm{D}$, Fehlings MG: Occipitocervical reconstruction with the Ohio Medical Instruments Loop: results of a multicenter evaluation in 30 cases. J Neurosurg 98 (3 Suppl):239-246, 2003

27. Suk KS, Baek JH, Park JO, Kim HS, Lee HM, Kwon JW, et al: Postoperative quality of life in patients with progressive neuromuscular scoliosis and their parents. Spine J 15:446453,2015

28. Vetter TR, Bridgewater CL, McGwin G Jr: An observational study of patient versus parental perceptions of health-related quality of life in children and adolescents with a chronic pain condition: who should the clinician believe? Health Qual Life Outcomes 10:85, 2012
29. Wills BP, Jencikova-Celerin L, Dormans JP: Cervical spine range of motion in children with posterior occipitocervical arthrodesis. J Pediatr Orthop 26:753-757, 2006

30. Xuan J, Kirchdoerfer LJ, Boyer JG, Norwood GJ: Effects of comorbidity on health-related quality-of-life scores: an analysis of clinical trial data. Clin Ther 21:383-403, 1999

\section{Disclosures}

The authors report no conflict of interest concerning the materials or methods used in this study or the findings specified in this paper.

\section{Author Contributions}

Acquisition of data: Vedantam, Hansen, Briceño, Brayton. Analysis and interpretation of data: Jea, Vedantam. Drafting the article: Jea, Vedantam. Critically revising the article: Jea. Reviewed submitted version of manuscript: Jea. Study supervision: Jea.

\section{Correspondence}

Andrew Jea, Section of Pediatric Neurosurgery, Indiana University School of Medicine, Goodman Campbell Brain and Spine, Riley Hospital for Children, 705 Riley Hospital Dr., Indianapolis, IN 46202. email: andrewjeamd@gmail.com. 